\title{
The scope of operative general paediatric surgical diseases in South Africa-the Chris Hani Baragwanath experience
}

\author{
Maame Tekyiwa Botchway ${ }^{1 *}$ (D), Deirdre Kruger ${ }^{2}$, Charles Adjei Manful ${ }^{3}$ and Andrew Grieve ${ }^{1}$
}

\begin{abstract}
Background: Infectious diseases have always been the lime light of global health with very little focus on childhood surgical conditions despite the fact that children constitute about half of the population in LMICs. A significant proportion of the burden of global disease can be reduced by surgical intervention. South Africa is one of the pioneers of the practice of paediatric surgery in Africa with a great burden of paediatric surgical conditions.

Few studies, if any, have investigated the burden of operative paediatric surgical procedures in South Africa. Therefore, this retrospective study aimed to look at the scope of operative paediatric surgical procedures at the Chris Hani Baragwanath Academic Hospital (CHBAH) based in Johannesburg, South Africa, and reports on the numbers of elective and emergency procedures over a 12-month study period.

Results: There were 1699 operative general paediatric surgical procedures of which 61.7\% were electives and 38.3\% were emergencies. The scope of general paediatric surgical conditions operated on fell under the categories of congenital anomalies, infections and tumours. Of these, surgeries for congenital anomalies were performed in almost all the subspecialties.
\end{abstract}

Conclusion: There is a high operative paediatric surgical burden at the CHBAH. The role of paediatric surgical care as an essential component of global health cannot be underrated.

Keywords: Paediatric surgical diseases, Congenital anomalies, Operative burden, South Africa, Global surgery

\section{Background}

Africa constitutes less than one fifth of the world's population yet contributes $25 \%$ of the global burden of disease [1]. Where children under the age of 15 years make up $26 \%$ of the world's population, they make up $43 \%$ of the population in sub-Saharan Africa. Furthermore, it is estimated that the population of many African countries will at least double by 2050, with Africa's youth rising to $35 \%$ of the world youth total by then [1]. Surgical conditions account for $6-12 \%$ of all paediatric visits and contribute to up a third of all childhood mortalities [2]. According to

\footnotetext{
* Correspondence: maametekyiwa@hotmail.com

'Department Surgery, Division of Paediatric Surgery, School of Clinical Medicine, Faculty of Health Sciences, University of Witwatersrand, Johannesburg, Gauteng, South Africa

Full list of author information is available at the end of the article
}

Bickler's group, about $90 \%$ of children living in low- and middle-income countries (LMICs) will have a surgical treatable condition by the age of 15 years [2] and, if not treated, can cause severe morbidity and mortality [3]. Surgical conditions thus play a significant role in the overall burden of paediatric disease in LMICs. Recently, Butler's group used population data from four LMICs and concluded that there is a high burden of unmet surgical need, with almost $20 \%$ of children requiring surgery and $62 \%$ of those children having at least one unmet surgical need [4].

Irrespective of its importance, little attention is given to paediatric surgical care in LMICs. Until recently, paediatric surgical care was seen as 'the neglected step child of global health' and, as it was not considered an essential service, excluded in many funded programmes both nationally and internationally [3]. Paediatric surgical care is generally seen

\section{Springer Open}

(c) The Author(s). 2021 Open Access This article is licensed under a Creative Commons Attribution 4.0 International License, which permits use, sharing, adaptation, distribution and reproduction in any medium or format, as long as you give appropriate credit to the original author(s) and the source, provide a link to the Creative Commons licence, and indicate if changes were made. The images or other third party material in this article are included in the article's Creative Commons licence, unless indicated otherwise in a credit line to the material. If material is not included in the article's Creative Commons licence and your intended use is not permitted by statutory regulation or exceeds the permitted use, you will need to obtain permission directly from the copyright holder. To view a copy of this licence, visit http://creativecommons.org/licenses/by/4.0/. 
as an expensive specialty due to the peculiar surgical conditions, distinct anaesthetic challenges and unique perioperative needs. Moreover, the care of these children could be lifelong and require frequent follow-ups until adulthood.

There is a significant volume of operative procedures globally with an estimation of 312.9 million operations in 2012 [5]. Due to the socioeconomic conditions in resource-constrained LMICs, differences exist between developing and developed countries in the patterns of disease and practice of paediatric surgical care [3]. Despite the perceived burden of paediatric surgical diseases in developing countries, there is scarce epidemiological data, making it difficult to assess the actual surgical burden of the paediatric population [6].

In a review of the surgical workforce in South Africa in 2017, Dell published results showing that there were only 5.55 paediatric surgeons per one million population under 14 years of age, with an average age of 39.5 years and 55\% male (Dell, 2017). This only left a workforce of only thirty giving a ratio of one specialist to every two million population. These figures fell far below developed countries such as the United States of America (USA) of one paediatric surgeon to approximately one hundred and eight thousand children as at 2006 (Polley et al. 2009).

South Africa is one of the pioneers of the practice of paediatric surgery in Africa. Nevertheless, a dearth of specialist paediatric surgeons in South Africa is a major obstacle in the effective delivery of paediatric surgical care. In 2015, Dell reported 0.80 paediatric surgeons per million total population in South Africa, with four provinces in the country not having one, compared to 8.20 paediatric surgeons per million total population in the USA [7]. This falls short of the one paediatric surgeon per 500,000 population recommended internationally [8].

The Chris Hani Baragwanath Academic Hospital (CHBAH) in Soweto, Johannesburg, is one of the institutions in sub-Saharan Africa making giant strides in the provision of paediatric surgical services in the State sector. It is the biggest hospital in the Southern Hemisphere and the fourth largest in the world. Its main catchment area is in Soweto serving a local population of over three million people [9]. CHBAH also acts as a major referral centre for the Gauteng Province and neighbouring provinces. The Paediatric Surgical Unit of the CHBAH is a highly specialized one managing complex cases from hepatobiliary to colorectal pathologies. There are two theatres dedicated to the paediatric surgical unit at the CHBAH (a neonatal theatre and a general paediatric theatre). Elective operative procedures are performed four times a week at the neonatal theatre and three times a week at the general paediatric theatre. Emergency surgeries are performed any time of the day and week on availability of an anaesthetist. The large population it serves coupled with multiple referrals and limited resources makes theatre days very busy with many cold cases waiting.

Few studies, if any, have investigated the burden of operative paediatric surgical procedures in South Africa. Therefore, this study aimed to look at the scope of operative paediatric surgical procedures at the $\mathrm{CHBAH}$ based in Johannesburg, South Africa, and reports on:

- The numbers of elective and emergency procedures over the 12-month study period

- The most common procedures performed with respect to age, gender and subspecialty

\section{Methods}

Ethical approval was obtained for this cross-sectional, descriptive study from the Human Research Ethics Committee (Ethics Certificate number M180406). Operative data over a 12-month study period from 1st January 2017 to 31st December 2017 were retrospectively collected from theatre logbooks at the Paediatric Surgical Unit of the CHBAH.

In order to ensure accuracy and avoid missing data points, data was cross-referenced with the monthly statistics of the Unit as well as operative logbooks of other paediatric surgical registrars. As per the admission age cut-off of the CHBAH Paediatric Surgical Unit, all patients 10 years old and younger were included in our study. Burn operative procedures were excluded from the study cohort because burns are managed by plastic surgeons in other hospitals and countries.

Demographic and clinical data were recorded and included the date of the procedure, age, gender, nature and type of the procedure performed. Data collected was captured unto an excel sheet and subsequently imported and analysed using STATA version 15.0. Data was

Table 1 Demographic and clinical characteristics in paediatric surgical patients

\begin{tabular}{llll}
\hline Parameters & $\begin{array}{l}\text { All } \\
\text { procedures }\end{array}$ & \multicolumn{2}{l}{ Paediatric surgical procedures } \\
\cline { 3 - 4 } & Elective & Emergency \\
\hline n, number (\%) & $1699(100 \%)$ & $1049(61.7 \%)$ & $650(38.3 \%)$ \\
Age, years (IQR) & $1.0(0.0-4.0)$ & $2.0(0.0-4.0)$ & $1.0(0.0-4.0)$ \\
Age groups, $n(\%)$ & & & \\
$\quad<28$ days & $246(14.5 \%)$ & $48(4.6 \%)$ & $198(30.5 \%)$ \\
28 days-12 months & $446(26.3 \%)$ & $322(30.7 \%)$ & $125(19.2 \%)$ \\
$1-5$ years & $609(35.8 \%)$ & $434(41.4 \%)$ & $174(26.8 \%)$ \\
5-10 years & $398(23.4 \%)$ & $245(23.4 \%)$ & $153(23.5 \%)$ \\
Male gender, $n(\%)$ & $1029(60.6 \%)$ & $676(64.4 \%)$ & $353(54.3 \%)$ \\
\hline
\end{tabular}

Abbreviation: IQR interquartile range 


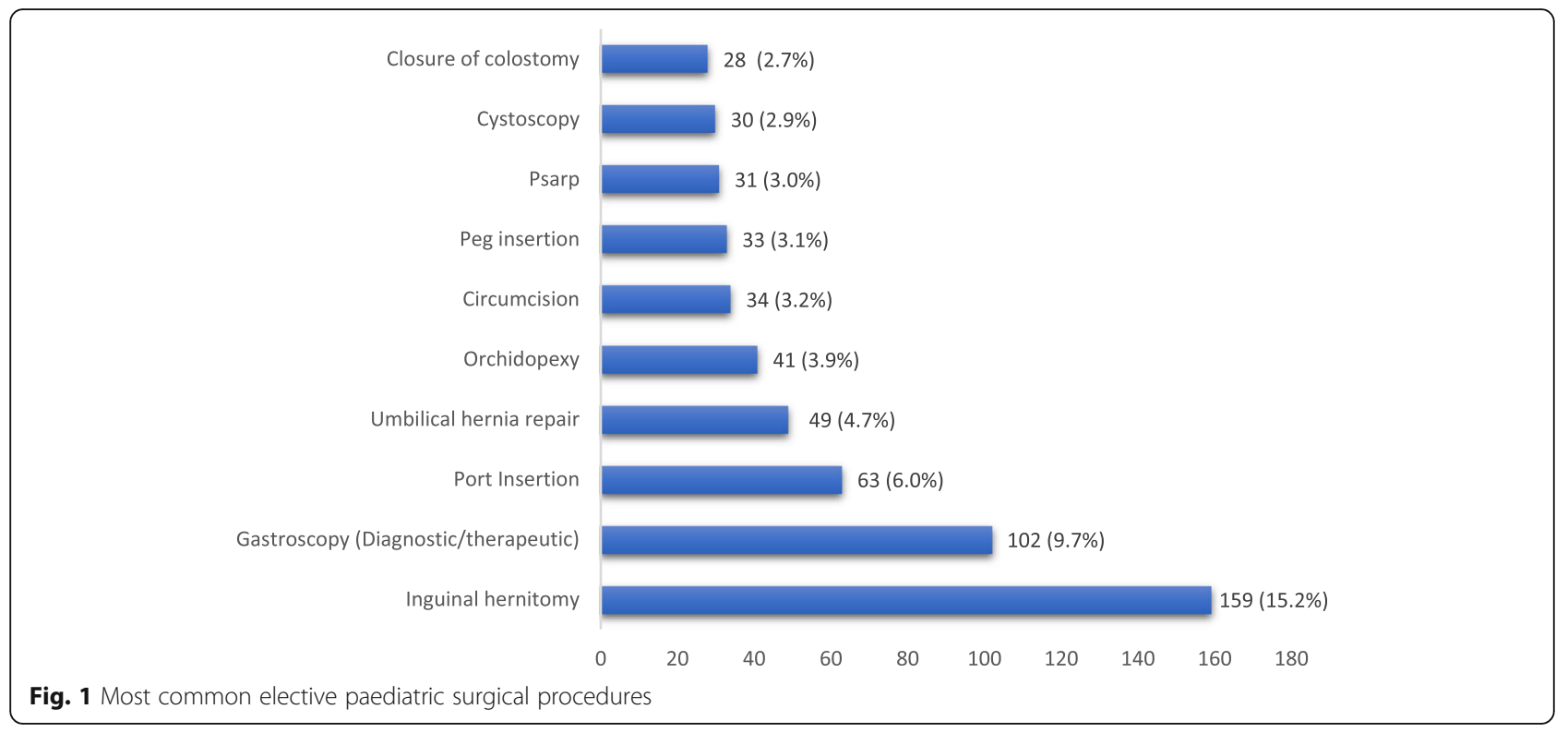

subsequently grouped according to age (e.g. < 30 days old, 1 to 6 months, 6 months to 1 year) and system involved. Descriptive data was generated from the analysis.

\section{Results}

The demographic and clinical characteristics of the study cohort are shown in Table 1. A total of 1699 procedures were performed over the 1-year study period. The median age for the study cohort was 1 year with an interquartile range (IQR) of $0-4$ years and a male to female ratio of 1.5:1. The majority of the procedures were performed in children under 5 years $(76.6 \%)$.

Out of the 1699 procedures performed, 1049 (61.7\%) were elective procedures and $650(38.3 \%)$ were emergency procedures. Of the elective procedures, inguinal herniotomy was the most frequent procedure performed at $27.8 \%$, followed by diagnostic or therapeutic gastroscopy at $17.9 \%$ (Fig. 1). From Fig. 2, incision and drainage

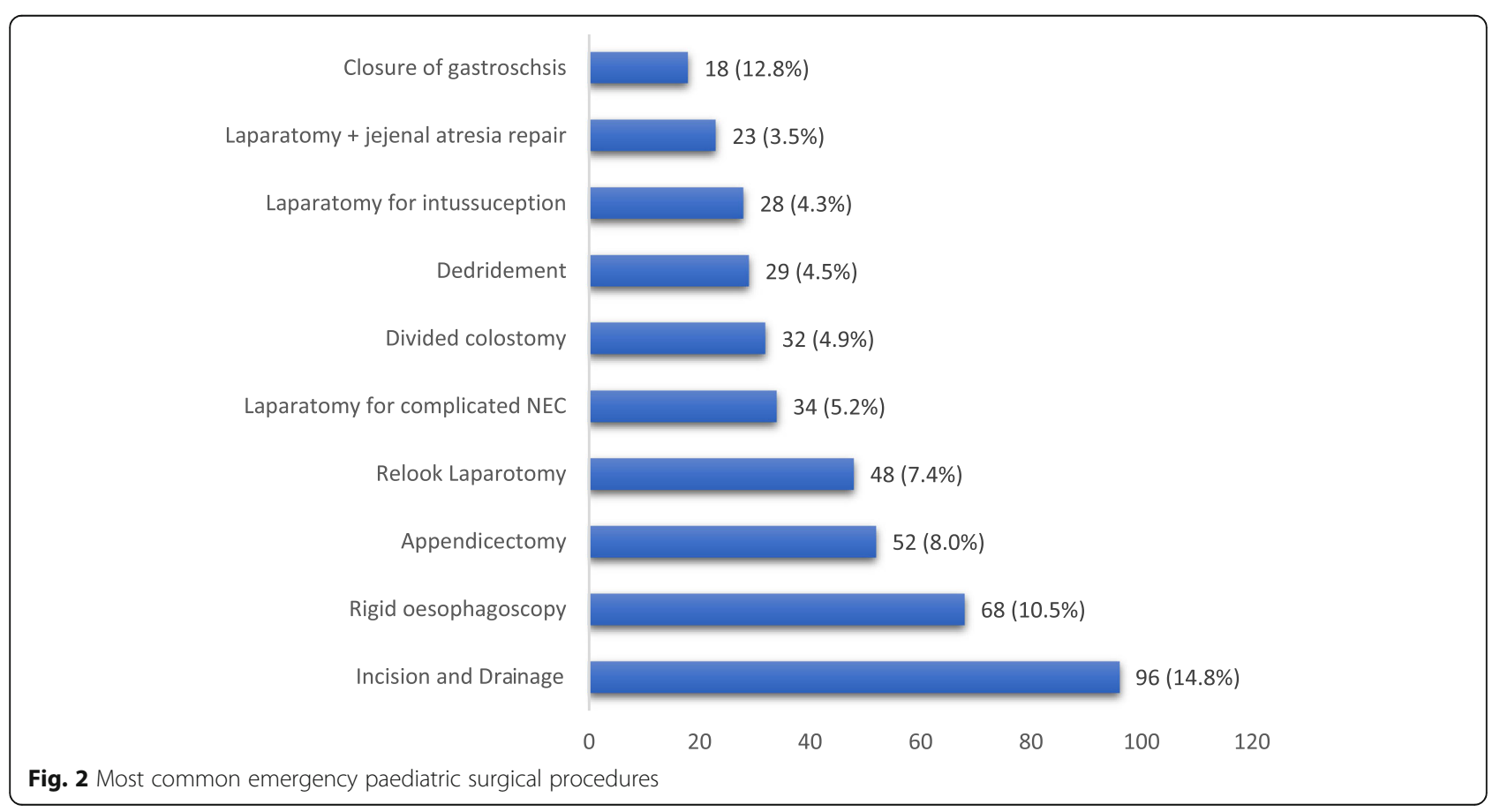




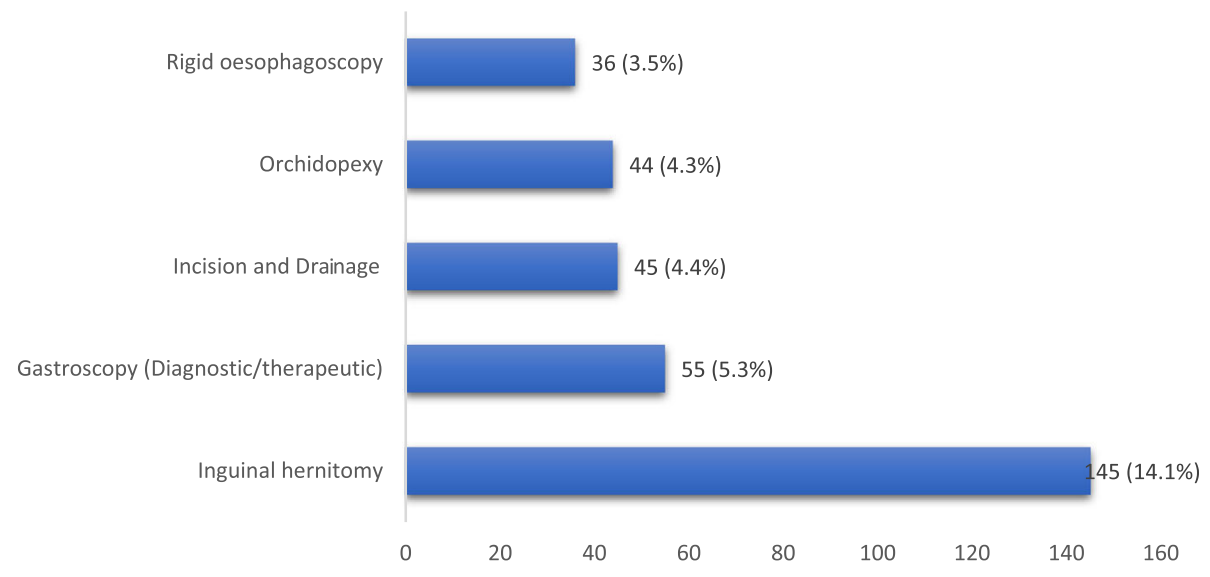

a: Bar Chart Showing the Distribution of Procedures for Males

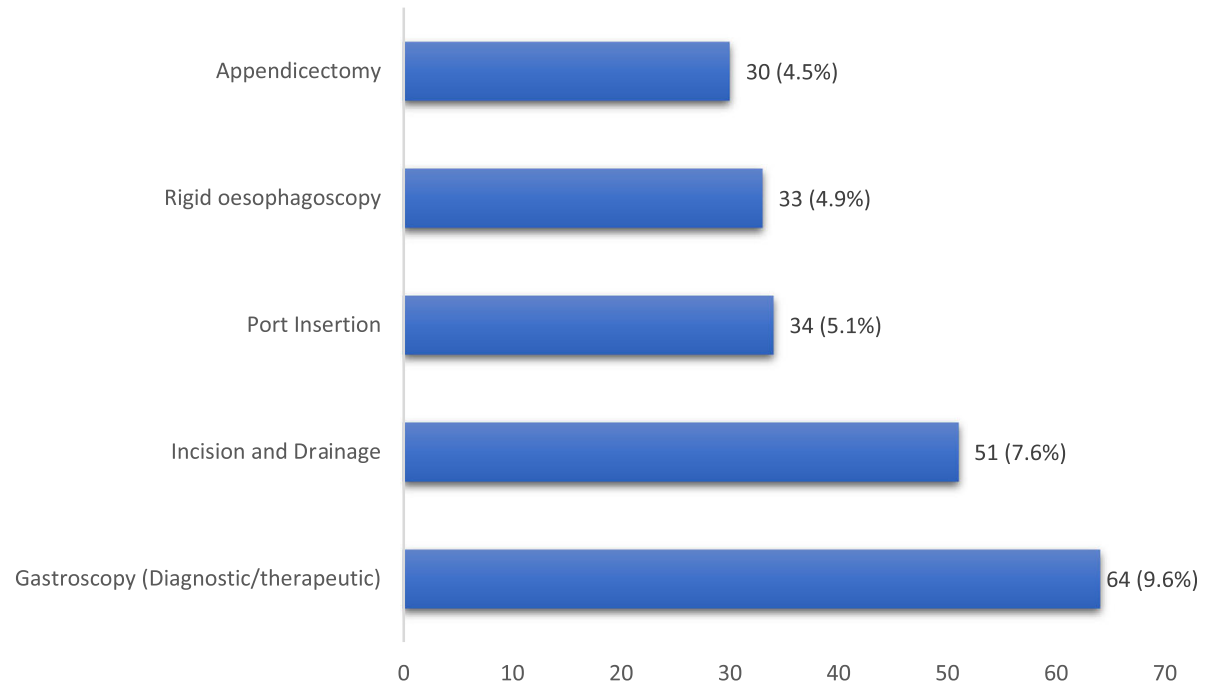

b: Bar Chart Showing the Distribution of Procedures for Females

Fig. 3 a Bar chart showing the distribution of procedures for males. $\mathbf{b}$ Bar chart showing the distribution of procedures for females

of abscesses (22.4\%) was the most frequent emergency procedure performed, followed by rigid oesophagoscopy (15.9\%).

\section{Paediatric surgical procedures by gender}

From Fig. 3, inguinal herniotomy was the most common procedure performed in males (14.1\%, Fig. 3a), whereas gastroscopy was the most common procedure performed in females (30.2\%, Fig. 3b).

\section{Paediatric surgical procedures by age}

As evidenced in Table 2, both laparotomy for complicated necrotizing enterocolitis $(25.2 \%)$ and divided colostomy (25.2\%) were the most common procedures performed in neonates. Inguinal herniotomy was frequently performed in children under 1 year old.
Appendicectomy was the most common procedure performed in the older age group.

\section{Procedure by subspecialty}

As shown in Fig. 4, gastrointestinal tract (GIT) surgeries were the most common procedures performed in this study $(49.5 \%)$, followed by general paediatric surgical

Table 2 Most common paediatric surgical procedures by age group

\begin{tabular}{lll}
\hline Age group & Commonest procedure & $\boldsymbol{n}(\%)$ \\
\hline$<28$ days & $\begin{array}{l}\text { Laparotomy for complicated NEC } \\
\text { and divided colostomy }\end{array}$ & $60(3.5 \%)$ \\
28 days-12 months & Inguinal herniotomy & $77(4.5 \%)$ \\
$1-5$ years & Gastroscopy (diagnostic/therapeutic) & $51(3 \%)$ \\
$5-10$ years & Appendicectomy & $46(2.7 \%)$ \\
\hline
\end{tabular}

Abbreviation: NEC necrotizing enterocolitis 


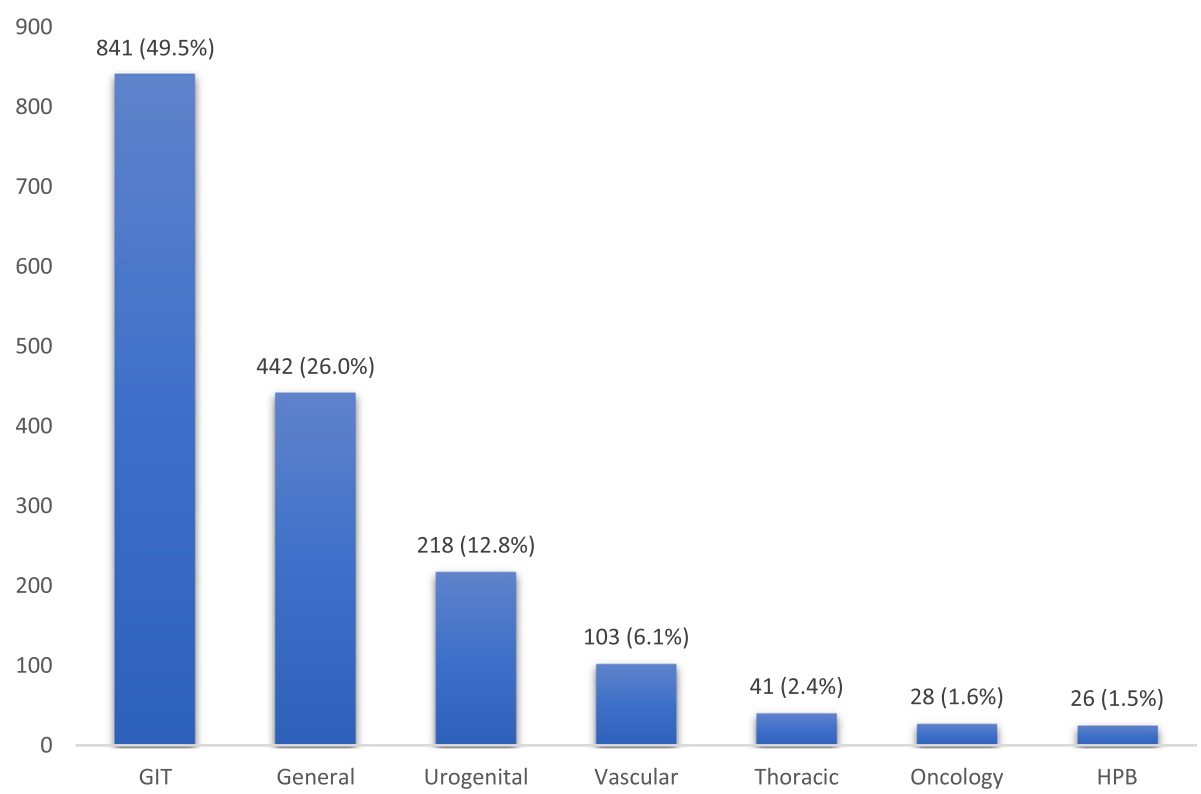

Fig. 4 The most common paediatric surgical procedures per subspecialty

cases $(26.0 \%)$. The least performed surgeries were oncological and hepatobiliary procedures.

Table 3 shows the paediatric surgical procedures per subspecialty. The majority (14.1\%) of GIT cases were gastroscopy (diagnostic/therapeutic). Inguinal herniotomy was the most prevalent (35.7\%) general cases. About two thirds (61.2\%) of vascular procedures were port insertion. More than half of HBP procedures were Kasai portoenterostomy.

\section{Discussion}

There is scarcity in the literature on paediatric surgical conditions in sub-Saharan Africa with even more scanty data on operative paediatric surgical conditions [4]. South Africa is no exception despite the fact that it houses the largest hospital in the Southern Hemisphere. This study gives a good insight to the scope of operative paediatric surgical conditions at the CHBAH. The Paediatric Surgical Unit of the $\mathrm{CHBAH}$ is a busy unit providing paediatric surgical services round the clock. It extends its coverage not only to the Gauteng Province but also to other neighbouring provinces and other nations in Africa. The unit manages general paediatric surgical conditions, paediatric trauma and complex and highly specialized paediatric surgical conditions. Even though the age cut-off for the Unit is 10 years, there are some children above this number who are managed in the Unit, most of which are colorectal, urology and oncology cases.

The mid-year population of South Africa as at 2018 was 57.7 million with 15.8 million of the population being $0-4$ years [10]. The population of Soweto, a major drainage area of CHBAH, is 1.2 million [10]. As per the department's statistics, a total of 8516 children visited the outpatient department of the Paediatric Surgical Unit of the CHBAH in 2018. This together with our cohort of 1699 surgeries performed during our 12-month study period confirms the high demand of paediatric surgical care in LMICs [11]. The male preponderance in the study is in keeping with other literature $[12,13]$.

Children living in Africa are affected by a broad spectrum of surgical conditions categorized under injuries, congenital anomalies, surgical infections and tumours [12]. In sub-Saharan Africa, the bulk of paediatric surgical admissions needing surgical intervention were due to injuries, congenital anomalies and infections [14]. In our audit, the common diagnostic categories needing intervention were mainly congenital anomalies, surgical infections and tumours. Trauma was not that common because most of them are usually managed conservatively without needing operative intervention $[15,16]$. In this study, congenital anomalies ranked top in almost all the subspecialties of paediatric surgical procedures. This finding is in keeping with available data [3,12], and our study therefore supports the view that congenital anomalies make up the majority of paediatric surgical procedures in sub-Saharan Africa [12]. This is not surprising considering the fact that globally, congenital anomalies took 14th position in the overall burden of diseases with DALYs of 52 billion [17]. Common congenital anomalies operated on as elective cases were inguinal hernias, umbilical hernias and undescended testes. The latter is in keeping with a study by Abantanga and Amaning in 2002 that reported on elective paediatric surgical admissions at a referral centre in Kumasi, Ghana [18]. 
Table 3 Most common paediatric surgical procedures per subspecialty category

\begin{tabular}{|c|c|c|}
\hline Category & $\begin{array}{l}n(\%) \text { of all } \\
\text { procedures }\end{array}$ & $\begin{array}{l}\text { Percentage of } \\
\text { category }\end{array}$ \\
\hline \multicolumn{3}{|l|}{ Key procedure } \\
\hline$\overline{\text { GIT }}$ & 841 (49.5\%) & \\
\hline $\begin{array}{l}\text { Gastroscopy (diagnostic/ } \\
\text { therapeutic) }\end{array}$ & $119(7.0 \%)$ & 14.1 \\
\hline Rigid oesophagoscopy & 69 (4.1\%) & 8.0 \\
\hline Appendicectomy & $53(3.1 \%)$ & 6.3 \\
\hline Relook laparotomy & $48(2.8 \%)$ & 5.7 \\
\hline Divided colostomy & $39(2.3 \%)$ & 4.6 \\
\hline General & $442(26.0 \%)$ & \\
\hline Inguinal herniotomy & $158(9.3 \%)$ & 35.7 \\
\hline Incision and drainage & $96(5.7 \%)$ & 21.7 \\
\hline Umbilical hernia repair & 49 (28.9\%) & 11.1 \\
\hline Debridement & $29(1.7 \%)$ & 6.6 \\
\hline Excision biopsy & $26(1.5 \%)$ & 5.9 \\
\hline Urogenital & $218(12.8 \%)$ & \\
\hline Orchidopexy & $44(2.6 \%)$ & 20.2 \\
\hline Circumcision & $36(2.1 \%)$ & 16.5 \\
\hline Cystoscopy & $30(1.8 \%)$ & 13.8 \\
\hline Hypospadias repair & $20(1.2 \%)$ & 9.2 \\
\hline Cauterisation of genital warts & $18(1.1 \%)$ & 8.3 \\
\hline Vascular & $103(6.1 \%)$ & \\
\hline Port insertion & $63(3.7 \%)$ & 61.2 \\
\hline Port removal & $32(1.9 \%)$ & 31.1 \\
\hline Above knee amputation & $4(0.2 \%)$ & 3.9 \\
\hline Quinton line insertion & $2(0.1 \%)$ & 1.9 \\
\hline Thoracic & $41(2.4 \%)$ & \\
\hline OA/TOF repair & $17(1.0 \%)$ & 41.5 \\
\hline Rigid bronchoscopy & $10(0.6 \%)$ & 24.4 \\
\hline Repair of CDH & $3(0.2 \%)$ & 7.3 \\
\hline Aortopexy & $2(0.1 \%)$ & 4.9 \\
\hline $\begin{array}{l}\text { Laryngoscopy + removal of } \\
\text { coin }\end{array}$ & $2(0.1 \%)$ & 4.9 \\
\hline Oncology & $28(1.7 \%)$ & \\
\hline Nephrectomy & $7(0.4 \%)$ & 25 \\
\hline $\begin{array}{l}\text { Excision of sacrococcygeal } \\
\text { teratoma }\end{array}$ & $4(0.2 \%)$ & 14.3 \\
\hline Excision of adrenal mass & $2(0.1 \%)$ & 7.1 \\
\hline Right orchidectomy & $2(0.1 \%)$ & 7.1 \\
\hline HPB & $26(1.5 \%)$ & \\
\hline Kasai portoenterostomy & 15 (0.9\%) & 57.7 \\
\hline Open liver biopsy & $5(0.3 \%)$ & 19.2 \\
\hline OTC + liver biopsy & $5(0.3 \%)$ & 19.2 \\
\hline
\end{tabular}

Abbreviations: $C D H$ congenital diaphragmatic hernia, GIT gastrointestinal tract, HPB hepatopancreatobiliary, OA/TOF oesophageal atresia with tracheooesophageal fistula, OTC on-table cholangiography
In a study on the scope of emergency paediatric surgical cases seen at a teaching hospital in Tanzania over a 1-year period [19], the authors reported that of the 414 paediatric operative procedures performed, $74 \%$ were elective and $26 \%$ were emergency procedures, and the two most common emergency procedures were for bowel obstruction and peritonitis. From our study, emergency operative procedures accounted for $38.3 \%$ of the total procedures performed and, in contrast to the abovementioned study, our two most common procedures were incision and drainage for abscesses and rigid oesophagoscopy for ingested foreign body material.

During the era of the Millennium Development Goals, there was a significant global reduction in mortality for children under 5 years old with neonatal mortality however lagging behind [20, 21]. The third sustainable development goal aims to 'end preventable deaths of newborns and children under 5 years of age, with all countries aiming to reduce neonatal mortality to at least as low as 12 per 1000 live births and under- 5 mortality to at least as low as 25 per 1000 live births by 2030' [22]. Neonatal surgery has the likelihood of being a cost-effective health intervention considering the fact that these conditions have no alternative form of management but surgical. The actual burden of neonatal surgical diseases in Africa is not known. A survey in Africa however revealed that neonatal surgical diseases contribute to about 10 to $20 \%$ of the workload of paediatric surgeons in this region [23]. This is confirmed in our study where $14 \%$ of the surgeries performed in the cohort were due to neonatal conditions. The little literature available shows that the workload of neonatal surgery in major referral centres in sub-Saharan Africa has very little variation [24]. In a study by Ameh looking at Neonatal Surgery in Africa, 50\% of the 626 neonatal procedures performed at the Jos University Teaching hospital in Nigeria over a 10-year period (January 2001-December 2010) were emergency procedures [25]. In the same study, $40 \%$ of the 516 neonatal surgeries performed over a 10 -year period at the Ahmadu Bellow University Teaching Hospital also in Nigeria were emergency procedures [25]. The difference in proportions is quite wide in our study with $80.5 \%$ of the 246 procedures performed during the study year. There are so many reasons for this increased number. The variation of cases in their study was however similar to the common neonatal conditions operated on in our study. Congenital anomalies still ranked top in these conditions.

A limitation of our study is the retrospective study design, and as a result, some information may not have been recorded. 


\section{Conclusion}

Our study gives a good perspective on the scope of operative paediatric surgical conditions in Johannesburg. Most of the procedures performed were for congenital anomalies. This is not surprising considering the fact that congenital anomalies are one of the leading causes of under 5 mortality globally, thus contributing significantly to the burden of paediatric surgical diseases. It is therefore imperative to strengthen paediatric surgical services especially in LMICs in order to achieve the third Sustainable Development Goal.

In conclusion, despite the fact that the practice of Paediatric Surgery is advancing globally, there is still a deficiency in paediatric surgical care in LMICs carrying a significant burden of disease, especially in children. Even though the disease burden may be similar across sub-Saharan Africa, the scope of paediatric surgery may be different between institutions, as well as from one country to the next country.

Further research needs to be done in other teaching hospitals in Johannesburg and South Africa as a whole to better determine the operative paediatric surgical burden nationally. This will form a basis of good evidence to policy makers and non-governmental organizations (NGOs) on the need to include paediatric surgery in funded programmes.

There is also the need for other researchers and clinicians in LMICs to look at the scope of paediatric surgical conditions in each region and explore the barriers to providing effective and efficient paediatric surgical care.

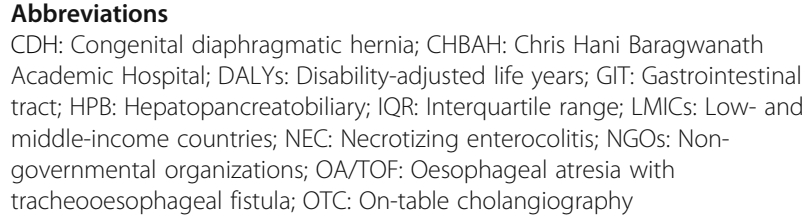

$\mathrm{CDH}$ : Congenital diaphragmatic hernia; $\mathrm{CHBAH}$ : Chris Hani Baragwanath Academic Hospital; DALYs: Disability-adjusted life years; GIT: Gastrointestinal tract; HPB: Hepatopancreatobiliary; IQR: Interquartile range; LMICs: Low- and middle-income countries; NEC: Necrotizing enterocolitis; NGOs: Nongovernmental organizations; OATTOF: Oesophageal atresia with tracheooesophageal fistula; OTC: On-table cholangiography

\section{Acknowledgements}

I would like to acknowledge my colleague paediatric surgical registrars for giving me their logbooks to cross-reference my data.

\section{Authors' contributions}

MTB: concept, data collection, analysis and write up. DK: literature review and supervised manuscript write up. CAM: statistical work and analysis. AG: literature review and supervised manuscript write up. All authors have read and approved the manuscript.

\section{Funding}

Not applicable.

\section{Availability of data and materials}

The dataset used and analysed during the current study is available from the corresponding author on reasonable request.

\section{Ethics approval and consent to participate}

This article does not contain any studies with human participants or animals performed by any of the authors. Ethical approval with certificate number M180406 (available on request) was received from the Human Research Ethics Committee.

\section{Consent for publication}

Consent to publish was received from the Department of Paediatric Surgery.

\section{Competing interests}

Dr Maame Tekyiwa Botchway declares that she has no competing interest.

Dr Deirdre Kruger declares that she has no competing interest.

Dr Adjei declares that he has no competing interest.

Dr Grieve declares that he has no competing interest.

\section{Author details}

${ }^{1}$ Department Surgery, Division of Paediatric Surgery, School of Clinical Medicine, Faculty of Health Sciences, University of Witwatersrand, Johannesburg, Gauteng, South Africa. ${ }^{2}$ Department of Surgery, School of Clinical Medicine, Faculty of Health Sciences, University of Witwatersrand, Johannesburg, Gauteng, South Africa. ${ }^{3}$ Department of Epidemiology, School of Clinical Medicine, Faculty of Health Sciences, University of Witwatersrand, Johannesburg, Gauteng, South Africa.

Received: 26 May 2020 Accepted: 20 October 2020

Published online: 18 January 2021

\section{References}

1. Population Reference Bureau, (2018) Africa's youthful population: risk or opportunity? - Population Reference Bureau. [online] Available at: https:// www.prb.org/africasyouthfulpopulation/ [Accessed $13^{\text {th }}$ May, 2019].

2. Bickler SW, Telfer ML, Sanno-Duanda B. Need for paediatric surgery care in an urban area of The Gambia. Trop Doct 2003; 33: 91-4 pmid: 12680542.

3. Bickler SW, Rode H. Surgical services for children in developing countries. Bull World Health Organ. 2002;80(10):829-35.

4. Butler EK, Tran TM, Nagarajan N, et al. Epidemiology of pediatric surgical needs in low-income countries. PLoS One. 2017;12:e0170968. https://doi. org/10.1371/journal.pone.0170968.

5. Weiser et al. Estimate of the global volume of surgery in 2012: an assessment supporting improved health outcomes. Lancet. 2015 Apr 27;385 Suppl 2:S11. doi: 10.1016/S0140-6736(15)60806-6. Epub 2015 Apr 26.

6. Weiser, T.G., Regenbogen, S.E., Thompson et al. An estimation of the global volume of surgery: a modelling strategy based on available data. Lancet 2008; 372: 139-44. DOI: 10.1016/S0140-6736(08)60878-8 pmid: 18582931. DOI: 10.1016/S0140-736(08)60878-8.

7. Dell A, et al, Pediatric surgeon density in South Africa, J Pediatr Surg (2018), https://doi.org/https://doi.org/10.1016/j.jpedsurg.2017.11.067.

8. Royal College of Surgeons of England. Surgical workforce. Available from: https://www.rcseng.ac.uk/surgeons/surgical-standards/docs/2011-surgicalworkforcecensus-report; 2011.

9. Gauteng Province. Hospitals: Chris Hani Baragwanath Academic Hospital. [Online] Available at https://www.chrishanibaragwanathhospital.co.za (Accessed on $15^{\text {th }}$ July, 2018).

10. Statistics South Africa. 2018. Mid-year population estimates, 2018. Statistical Release P0302.

11. Poenaru D. The burden of pediatric surgical disease in low-resource settings: discovering it, measuring it, and addressing it. J Pediatr Surg. 2016; 51:216-20.

12. Bickler SW, Sanno-Daunda B. Epidemiology of paediatric surgical admissions to a government referral hospital in the Gambia. Bull World Health Organ. 2000;78(11):1330-6.

13. Paingha JA, Isesoma G. Pattern of paediatric surgical admissions in a tertiary hospital in a semi-urban community in the Niger Delta: a three-year review. International Journal of Tropical Disease and Health. 2014;4(1):45-51.

14. Bickler, S.W. Out of Africa: insights from a prospective pediatric surgery database. J Pediatr Surg. 2018;53:12-20 DOl: https://doi.org/https://doi.org/ 10.1016/j.jpedsurg.2017.10.009.

15. Rance $\mathrm{CH}$, Singh SJ, Kimble R. Blunt abdominal trauma in children. J Paediatr Child Health. 2000;36:213-215. [Google Scholar].

16. Velmahos GC, Zacharias N, Emhoff TA, Feeney JM, Hurst JM, Crookes BA, et al. Management of the most severely injured spleen. Arch Surg. 2010;145: 456-60.

17. Boyle B, Addor MC, Arriola L, Barisic I, Bianchi F, Csáky-Szunyogh M, et al. Estimating global burden of disease due to congenital anomaly: an analysis of European data. Arch Dis Child Fetal Neonatal Ed. 2018;103:F22-8.

18. Abatanga AF, Amaning EP. Pediatric elective surgical conditions as seen at a referral hospital in Kumasi, Ghana. ANZ J Surg. 2002;72:890-2. 
19. Mhando S, Young B, Lakhoo K. The scope of emergency paediatric surgery in Tanzania. Pediatr Surg Int. 2008;242:219-22.

20. You D, Jones $G$, Wardlaw T. Levels and trends in child mortality. UNICEF Bulletin; 2011.

21. Rajaratnam JK, Marcus JR, Flaxman AD, et al. Neonatal, postneonatal, childhood, and under-5 mortality for 187 countries, 1970-2010: a systematic analysis of progress towards millennium development goal 4. Lancet. 2010; 375(9730):1988-2008.

22. UN General Assembly, Transforming our world: the 2030 Agenda for Sustainable Development, 21 October 2015, A/RES/70/1, available at: https:// www.refworld.org/docid/57b6e3e44.html [accessed 13 June 2019].

23. Chirdan $L B$, Ameh EA, Abantanga FA, et al. Challenges of training and delivery of pediatric surgical services in Africa. J Pediatr Surg. 2010;45:610-8.

24. L.B. Chirdan, P.J. Ngiloi, E.A. Elhalaby Neonatal surgery in Africa Semin Pediatr Surg, 21 (2) (2012), pp. 151-159.

25. Ameh EA, Dogo PM, Nmadu PT. Emergency neonatal surgery in a developing country. Pediatr Surg Int. 2001;17:448-51.

\section{Publisher's Note}

Springer Nature remains neutral with regard to jurisdictional claims in published maps and institutional affiliations.

\section{Submit your manuscript to a SpringerOpen ${ }^{\circ}$ journal and benefit from:}

- Convenient online submission

- Rigorous peer review

- Open access: articles freely available online

High visibility within the field

- Retaining the copyright to your article

Submit your next manuscript at $\boldsymbol{\nabla}$ springeropen.com 